Diensthabende

\section{Augen auf!}

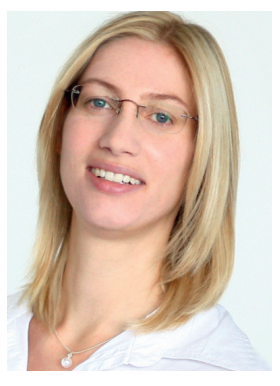

Der Fortschritt in der Medizin ist rasant. Beispiel Asthma: Bis vor knapp 130 Jahren das Theophyllin entdeckt wurde, waren Ärzte gegenüber diesem Leiden weitgehend machtlos. Heute helfen ihnen Verfahren wie Bodyplethysmografie und Prick-Test bei einer differenzierten Diagnose. Und bei der Therapie müssen sie nicht mehr auf mysteriöse Kräuter-Tinkturen zurückgreifen, sondern haben mit SABA, LABA, ICS \& Co eine breite Palette von Möglichkeiten. Mehr über diese Erfolgsgeschichte der Medizin auf Seite 42. Doch Vorsicht! Wer sich als Arzt darauf beschränkt, virtuos mit den Hightech-Optionen der modernen Medizin zu jonglieren, macht sich zum Knecht der eigenen Kunst. Haltet deshalb die Augen offen für die Missstände im Leben eurer Patienten, die sich nicht mit moderner Bildgebung nachweisen lassen! Was tut man zum Beispiel, wenn ein Kind auffällige Hämatome und Striemen zeigt und der Verdacht auf Kindesmisshandlung keimt? Tipps, wie in solch einer Situation verfahren werden sollte, geben wir auf Seite 26. Und noch einen Artikel möchte ich euch ans Herz legen: Auf S. 18 berichtet der Anästhesist Emmanuel Winkler von einem Einsatz für die Organisation Interplast in Indien. Er zeigt beispielhaft, wie man mit wenig Mitteln in der Medizin viel bewegen kann.

Beste Grüße, eure Ines Elsenhans

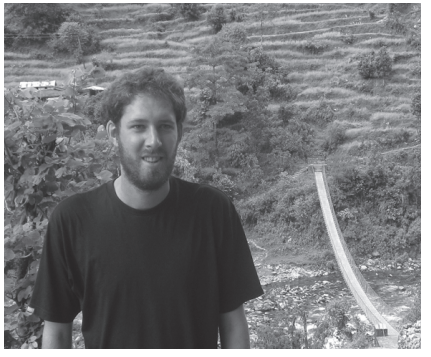

Emmanuel Winkler arbeitet als Anästhesist in Berlin. Während seines Studiums hat er Famulaturen in Afrika und Südamerika absolviert. In diesem Heft berichtet er über seinen ersten Auslandseinsatz als Arzt - in einem Team mit Plastischen Chirurgen der Hilfsorganisation „Interplast“ in Indien (S. 18).

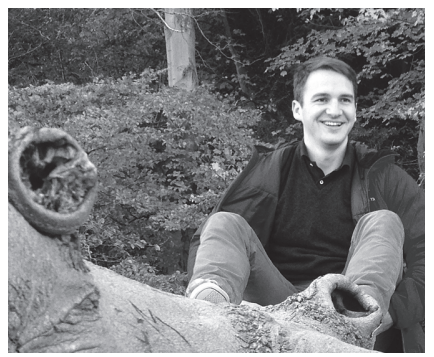

Dr. Benedikt Hofauer

ist HNO-Arzt mit Leib und Seele. Ob dabei wohl eine Rolle spielt, dass er seine erste intensive Erfahrung mit Medizin machte, als er mit sechs Jahren tonsillektomiert wurde? Über Indikation und Durchführung dieses häufigen Eingriffs hat er uns einen OP-Technik-Artikel geschrieben (S. 46).

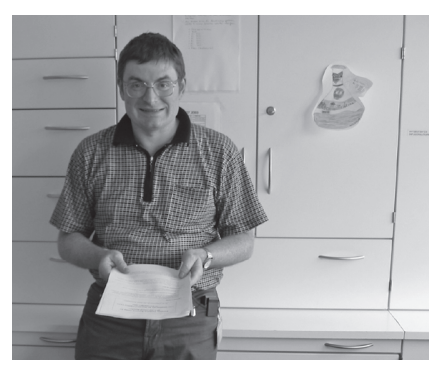

PD Dr. Martin Bald

kennt sich als Oberarzt in der Pädiatrie am Stuttgarter Olgahospital bestens mit den klassischen Kinderkrankheiten aus. In seinem Artikel verrät er uns unter anderem, wie man harmlose Exantheme von ernsten Erkrankungen, wie einer Meningokokken-Sepis, unterscheidet (S. 36). 